\title{
Anti Bohr - Quantum Theory and Causality
}

\author{
Ilija Barukčić* \\ Internist. Horandstrasse, DE-26441 Jever, Germany. \\ * Corresponding author. Tel.: 0700-56 5656 56; email: Barukcic@t-online.de \\ Manuscript submitted December 17, 2016; accepted February 3, 2017. \\ doi: 10.17706/ijapm.2017.7.2.93-111
}

\begin{abstract}
The political attitude and the ideology of a very small elite of physicists (Niels Bohr, Werner Heisenberg, Max Born and view other) played a major role in the construction of the Copenhagen Interpretation of quantum mechanics in the 1920s. Lastly, the hegemonic standard acausal Copenhagen Interpretation of quantum mechanics abandoned the principle of causality in quantum mechanics and opened a very wide door to mysticism, logical fallacies and wishful thinking in physics and in science as such. Historically, the Second International Congress for the Unity of Science (Copenhagen, June 21-26, 1936) tried to solve the problem of causality within physics but without a success. Thus far, 80 years after the Second International Congress for the Unity of Science this publication will expel Bohr's and Heisenberg's dogma of non-causality out of quantum mechanics and re-establish the unrestricted validity of the principle of causality at quantum level and under conditions of relativity theory by mathematizing the relationship between cause and effect in the form of the mathematical formula of the causal relationship $\mathrm{k}$. In contrast to Bohr, Heisenberg and other representatives of the Copenhagen interpretation quantum mechanics, a realistic interpretation of quantum theory grounded on the unrestricted validity of the principle of causality will expel any kind of mysticism from physics and enable a quantization of the gravitational field too.
\end{abstract}

Key words: Causality, quantum theory, relativity theory, unified field theory.

\section{Introduction}

Since ancient times, the principle of causality was generally regarded as the most fundamental of all principles, the demarcation line between science and non-science and our best candidate for a unique and fundamental description of the physical world. But it may be useful to point out that the principle of causality lost its scientific meaning at least since Heisenberg's publication of his uncertainty principle. Heisenberg's himself considered his uncertainty principle to be the new cornerstone of science as such. Heisenberg summarized his findings on the principle of causality in a general conclusion: "... so wird durch die Quantenmechanik die Ungültigkeit des Kausalgesetzes definitiv festgestellt" [1] or in broken English 'quantum mechanics has refuted the principle of causality definitely'. Apparently, even when Bohr himself refers to the principle of causality, he supports Heisenberg's position. In fact, Bohr tried to convince the assembly of scientists by explaining that the "so-called indeterminacy relations explicitly bear out the limitation of causal analysis" [2] Let us conclude this short overview with Bohr's dogmatic remark that "physics ... forces us to replace ... causality by ... complementarity" [3] By time, the extraordinary predictive successes of quantum mechanics in power and precision, supported, at least at first glance, more and more Heisenberg's uncertainty principle and the so-called Copenhagen interpretation 
of quantum mechanics. Still, the question is then what status shall we assign to Heisenberg's uncertainty principle [4]-[6] and to the principle of causality [7] since both are excluding each other. Now obviously, according to Heisenberg's own conclusion, one striking aspect of a successful mathematization of the relationship between cause and effect at quantum level implies another straightforward refutation of Heisenberg's uncertainty principle.

\section{Material and Methods}

\subsection{Definitions}

\section{Definition 1. Bernoulli trials}

A Bernoulli trial (or binomial trial) denotes a random experiment with exactly two possible outcomes, either a concrete eigenvalue or not a concrete eigenvalue i. e. all but the concrete eigenvalue. The mathematical formalization of the Bernoulli trial is denoted as the Bernoulli process. A random experiment may consists of performing $\mathrm{n}$ Bernoulli trials, each with the probability $p\left(j e_{t}\right)$ as associated with the eigenvalue jet, i. e. it is $t=+1, \ldots,+\mathrm{N}$.

\section{Definition 2. Bernoulli observable}

Let a Bernoulli random variable or a Bernoulli quantum mechanical observable be associated with a quantum mechanical operator. Let the Bernoulli quantum mechanical observable be determined by the fact that the same observable can take only two eigenvalues either +1 or +0 associated with some adequate probabilities and eigenfunctions.

Property. In the language of set theory we obtain i. e. $o C_{t}=\{+0,+1\}$.

\section{Definition 3. The expectation value of an effect at a single Bernoulli trial $t$}

Let ${ }_{j} e_{t}$ (an effect) denote an eigenvalue of a quantum observable ${ }_{R} E_{t}$. More precisely, let ${ }_{R} E_{t}$ denote the set of all possible eigenvalues $e_{t}$ at one single Bernoulli trial $t$, i. e. all possible outcomes of a measurement. Let $E\left({ }_{R} E_{t}\right)$ denote the denote the expectation value of the quantum observable ${ }_{R} E_{t}$. Let $\Psi\left({ }_{R} E_{t}\right)$ denote the wave function of ${ }_{R} E_{t}$. Let $\Psi^{*}\left({ }_{R} E_{t}\right)$ denote the complex-conjugate of the wave function of ${ }_{R} E_{t}$. Let $c\left({ }_{j} e_{t}\right)$ denote the complex coefficient as associated with the eigenvalue ${ }_{j} e_{t}$ while satisfying some normalization condition. Let $c^{*}\left(j e_{t}\right)$ denote complex conjugate of the complex coefficient as associated with the eigenvalue ${ }_{j} e_{t}$. Let $\psi\left(j e_{t}\right)$ denote the eigenfunction as associated with an eigenvalue ${ }_{j} e_{t}$ while satisfying some normalization condition. Let $\psi^{*}\left({ }_{j} e_{t}\right)$ denote complex conjugate of the eigenfunction as associated with the eigenvalue ${ }_{j} e_{t}$ while satisfying normalization. Let $p\left({ }_{j} e_{t}\right)$ denote the probability as associated with the eigenvalue ${ }_{j} e_{t}$. Let $\sigma\left(j e_{t}\right)^{2}$ denote the variance of an eigenvalue ${ }_{j} e_{t}$. Let $\sigma\left(j e_{t}\right)$ denote the standard deviation of an eigenvalue ${ }_{j} e_{t}$. Let $E\left(j e_{t}\right)$ denote the expectation value of an eigenvalue ${ }_{j} e_{t}$. In general, it is

$$
\begin{gathered}
E\left({ }_{j} e_{t}\right) \equiv{ }_{j} e_{t} \times p\left({ }_{j} e_{t}\right) \\
E\left({ }_{j} e_{t}\right) \equiv c\left({ }_{j} e_{t}\right) \times{ }_{j} e_{t} \times c^{*}\left({ }_{j} e_{t}\right) \\
E\left({ }_{j} e_{t}\right) \equiv \psi\left({ }_{j} e_{t}\right) \times{ }_{j} e_{t} \times \psi^{*}\left({ }_{j} e_{t}\right) \\
E\left({ }_{j} e_{t}\right) \equiv c\left({ }_{j} e_{t}\right) \times \psi\left({ }_{j} e_{t}\right)
\end{gathered}
$$

Properties.

Under conditions where $p\left(j e_{t}\right)=1$ it is $E\left(e_{t}\right)={ }_{j} e_{t}$. Further, from the definition before it follows that

$$
c\left({ }_{j} e_{t}\right) \equiv \frac{E\left({ }_{j} e_{t}\right)}{\psi\left({ }_{j} e_{t}\right)}
$$


In contrast and opposed to the usual statistical interpretation of the wavefunction, Aharonov et al. [8] provided already a trial of a new physical meaning to the expectation value of an observable for a single quantum system. According to mathematical statistics, the proof of following relationships can be found in literature. In general, it is

$$
\begin{gathered}
E\left({ }_{j} e_{t}^{2}\right) \equiv{ }_{j} e_{t}^{2} \times p\left({ }_{j} e_{t}\right) \\
E\left({ }_{j} e_{t}^{2}\right) \equiv c\left({ }_{j} e_{t}\right) \times{ }_{j} e_{t}^{2} \times c^{*}\left({ }_{j} e_{t}\right) \\
E\left({ }_{j} e_{t}^{2}\right) \equiv \psi\left({ }_{j} e_{t}\right) \times{ }_{j} e_{t}^{2} \times \psi^{*}\left({ }_{j} e_{t}\right) \\
E\left({ }_{j} e_{t}^{2}\right) \equiv{ }_{j} e_{t} \times E\left({ }_{j} e_{t}\right) \equiv c\left({ }_{j} e_{t}\right) \times{ }_{j} e_{t} \times \psi\left({ }_{j} e_{t}\right)
\end{gathered}
$$

The variance $\sigma\left(e_{t}\right)^{2}$ of an eigenvalue ${ }_{j} e_{t}$ follows as

$$
\begin{gathered}
\sigma\left({ }_{j} e_{t}\right)^{2} \equiv E\left({ }_{j} e_{t}^{2}\right)-E\left({ }_{j} e_{t}\right)^{2} \\
\sigma\left({ }_{j} e_{t}\right)^{2} \equiv\left({ }_{j} e_{t}^{2} \times p\left({ }_{j} e_{t}\right)\right)-\left({ }_{j} e_{t} \times p\left({ }_{j} e_{t}\right)\right)^{2}
\end{gathered}
$$

which is equivalent with

$$
\begin{gathered}
\sigma\left({ }_{j} e_{t}\right)^{2} \equiv{ }_{j} e_{t}^{2} \times\left(p\left({ }_{j} e_{t}\right)-p\left({ }_{j} e_{t}\right)^{2}\right) \\
\sigma\left({ }_{j} e_{t}\right)^{2} \equiv{ }_{j} e_{t}^{2} \times p\left({ }_{j} e_{t}\right) \times\left(1-p\left({ }_{j} e_{t}\right)\right)
\end{gathered}
$$

From this relationship, the eigenvalue $e_{t}$ can be derived as

$$
\left|{ }_{j} e_{t}\right| \equiv \sqrt[2]{\frac{\sigma\left({ }_{j} e_{t}\right)^{2}}{p\left({ }_{j} e_{t}\right) \times\left(1-p\left({ }_{j} e_{t}\right)\right)}} \equiv \frac{\sigma\left({ }_{j} e_{t}\right)}{\sqrt[2]{p\left({ }_{j} e_{t}\right) \times\left(1-p\left({ }_{j} e_{t}\right)\right)}}
$$

while the standard deviation $\sigma\left(j e_{t}\right)$ of an eigenvalue ${ }_{j} e_{t}$ is defined as

$$
\begin{gathered}
\sigma\left({ }_{j} e_{t}\right) \equiv \sqrt[2]{\left({ }_{j} e_{t}^{2} \times p\left({ }_{j} e_{t}\right)\right)-\left({ }_{j} e_{t} \times p\left({ }_{j} e_{t}\right)\right)^{2}} \\
\sigma\left({ }_{j} e_{t}\right) \equiv \sqrt[2]{{ }_{j} e_{t}^{2} \times p\left({ }_{j} e_{t}\right) \times\left(1-p\left({ }_{j} e_{t}\right)\right)}
\end{gathered}
$$

\section{Definition 4. The expectation value of a cause at a single Bernoulli trial $t$}

Let ${ }_{i} C_{t}$ (a cause) denote an eigenvalue of a quantum observable ${ }_{o} C_{t}$. In particular, let ${ }_{o} C_{t}$ denote the set of all possible eigenvalues ${ }_{i} C_{t}$ at one single Bernoulli trial $t$, i. e. all possible outcomes of a measurement. Let $E\left({ }_{o} C_{t}\right)$ denote the denote the expectation value of the quantum observable ${ }_{o} C_{t}$. Let $\Psi\left({ }_{o} C_{t}\right)$ denote the wave function of ${ }_{o} C_{t}$. Let $\Psi^{*}\left({ }_{o} C_{t}\right)$ denote the complex-conjugate of the wave function of ${ }_{o} C_{t}$. Let $c\left({ }_{i} C_{t}\right)$ denote the complex coefficient as associated with the eigenvalue ${ }_{i} C_{t}$ while satisfying some normalization condition. Let 
$c^{*}\left({ }_{i} c_{t}\right)$ denote complex conjugate of the complex coefficient as associated with the eigenvalue ${ }_{i} c_{t}$. Let $\psi\left({ }_{i} c_{t}\right)$ denote the eigenfunction as associated with an eigenvalue ${ }_{i} c_{t}$ while satisfying some normalization condition. Let $\psi^{*}\left({ }_{i} C_{t}\right)$ denote complex conjugate of the eigenfunction as associated with the eigenvalue ${ }_{i} C_{t}$ while satisfying normalization. Let $p\left({ }_{i} c_{t}\right)$ denote the probability as associated with the eigenvalue ${ }_{i} c_{t}$. Let $\sigma\left({ }_{i} c_{t}\right)^{2}$ denote the variance of an eigenvalue ${ }_{i} c_{t}$. Let $\sigma\left({ }_{i} c_{t}\right)$ denote the standard deviation of an eigenvalue ${ }_{i} c_{t}$. Let $E\left({ }_{i} c_{t}\right)$ denote the expectation value of an eigenvalue ${ }_{i} c_{t}$. In general, it is

$$
\begin{gathered}
E\left({ }_{i} c_{t}\right) \equiv{ }_{i} c_{t} \times p\left({ }_{i} c_{t}\right) \\
E\left({ }_{i} c_{t}\right) \equiv c\left({ }_{i} c_{t}\right) \times{ }_{i} c_{t} \times c^{*}\left({ }_{i} c_{t}\right) \\
E\left({ }_{i} c_{t}\right) \equiv \psi\left({ }_{i} c_{t}\right) \times{ }_{i} c_{t} \times \psi^{*}\left({ }_{i} c_{t}\right) \\
E\left({ }_{i} c_{t}\right) \equiv c\left({ }_{i} c_{t}\right) \times \psi\left({ }_{i} c_{t}\right)
\end{gathered}
$$

\section{Properties.}

Under conditions where $p\left({ }_{i} c_{t}\right)=1$ it is $E\left({ }_{i} C_{t}\right)={ }_{i} C_{t}$. According to mathematical statistics, we obtain the following relationships.

$$
\begin{gathered}
E\left({ }_{i} c_{t}^{2}\right) \equiv{ }_{i} c_{t}^{2} \times p\left({ }_{i} c_{t}\right) \\
E\left({ }_{i} c_{t}^{2}\right) \equiv c\left({ }_{i} c_{t}\right) \times{ }_{i} c_{t}^{2} \times c^{*}\left({ }_{i} c_{t}\right) \\
E\left({ }_{i} c_{t}^{2}\right) \equiv \psi\left({ }_{i} c_{t}\right) \times{ }_{i} c_{t}^{2} \times \psi^{*}\left({ }_{i} c_{t}\right) \\
E\left({ }_{i} c_{t}^{2}\right) \equiv{ }_{i} c_{t} \times E\left({ }_{i} c_{t}\right) \equiv c\left({ }_{i} c_{t}\right) \times{ }_{i} c_{t} \times \psi\left({ }_{i} c_{t}\right)
\end{gathered}
$$

The variance of an eigenvalue ${ }_{i} c_{t}$ follows as

$$
\begin{gathered}
\sigma\left({ }_{i} c_{t}\right)^{2} \equiv E\left({ }_{i} c_{t}^{2}\right)-E\left({ }_{i} c_{t}\right)^{2} \\
\sigma\left({ }_{i} c_{t}\right)^{2} \equiv\left({ }_{i} c_{t}^{2} \times p\left({ }_{i} c_{t}\right)\right)-\left({ }_{i} c_{t} \times p\left({ }_{i} c_{t}\right)\right)^{2}
\end{gathered}
$$

which is equivalent with

$$
\begin{gathered}
\sigma\left({ }_{i} c_{t}\right)^{2} \equiv{ }_{i} c_{t}^{2} \times\left(p\left({ }_{i} c_{t}\right)-p\left({ }_{i} c_{t}\right)^{2}\right) \\
\sigma\left({ }_{i} c_{t}\right)^{2} \equiv{ }_{i} c_{t}^{2} \times p\left({ }_{i} c_{t}\right) \times\left(1-p\left({ }_{i} c_{t}\right)\right)
\end{gathered}
$$

From this relationship, the eigenvalue of a cause ${ }_{i} c_{t}$ can be derived as

$$
\left|{ }_{i} c_{t}\right| \equiv \sqrt[2]{\frac{\sigma\left({ }_{i} c_{t}\right)^{2}}{p\left({ }_{i} c_{t}\right) \times\left(1-p\left({ }_{i} c_{t}\right)\right)}} \equiv \frac{\sigma\left({ }_{i} c_{t}\right)}{\sqrt[2]{p\left({ }_{i} c_{t}\right) \times\left(1-p\left({ }_{i} c_{t}\right)\right)}}
$$

while the standard deviation of an eigenvalue of a cause ${ }_{i} C_{t}$ is defined as 


$$
\begin{gathered}
\sigma\left({ }_{i} c_{t}\right) \equiv \sqrt[2]{\left({ }_{i} c_{t}^{2} \times p\left({ }_{i} c_{t}\right)\right)-\left({ }_{i} c_{t} \times p\left({ }_{i} c_{t}\right)\right)^{2}} \\
\sigma\left({ }_{i} c_{t}\right) \equiv \sqrt[2]{{ }_{i} c_{t}^{2} \times p\left({ }_{i} c_{t}\right) \times\left(1-p\left({ }_{i} c_{t}\right)\right)}
\end{gathered}
$$

\section{Definition 5. The co-variance of a cause and an effect at a single Bernoulli trial $\boldsymbol{t}$}

The covariance of two different eigenvalues ${ }_{i} c_{t}$ and ${ }_{j} e_{t}$, denoted by $\sigma\left({ }_{i} c_{t}, j e_{t}\right)$, is known to be defined as

$$
\begin{gathered}
\sigma\left({ }_{i} c_{t},{ }_{j} e_{t}\right) \equiv E\left({ }_{i} c_{t},{ }_{j} e_{t}\right)-\left(E\left({ }_{i} c_{t}\right) \times E\left({ }_{j} e_{t}\right)\right) \\
\sigma\left({ }_{i} c_{t},{ }_{j} e_{t}\right) \equiv\left({ }_{i} c_{t} \times{ }_{j} e_{t} \times p\left({ }_{i} c_{t},{ }_{j} e_{t}\right)\right)-\left(\left({ }_{i} c_{t} \times p\left({ }_{i} c_{t}\right)\right) \times\left({ }_{j} e_{t} \times p\left({ }_{j} e_{t}\right)\right)\right)
\end{gathered}
$$

where $\mathrm{p}\left({ }_{i} c_{t},{ }_{j} e_{t}\right)$ denotes the probability of the two eigenvalues ${ }_{i} c_{t}$ and ${ }_{j} e_{t}$ and $E\left({ }_{i} c_{t},{ }_{j} e_{t}\right)$ denotes the expectation value of the two different eigenvalues ${ }_{i} c_{t}$ and ${ }_{j} e_{t}$ at one single Bernoulli trial $t$. The equation before can be simplified as

$$
\sigma\left({ }_{i} c_{t},{ }_{j} e_{t}\right) \equiv\left({ }_{i} c_{t} \times{ }_{j} e_{t}\right) \times\left(p\left({ }_{i} c_{t},{ }_{j} e_{t}\right)-\left(p\left({ }_{i} c_{t}\right) \times p\left({ }_{j} e_{t}\right)\right)\right)
$$

where $p\left({ }_{i} c_{t},{ }_{j} e_{t}\right)$ denotes the joint probability of the eigenvalues ${ }_{i} c_{t}$ and ${ }_{j} e_{t}$. The joint probability between the eigenvalues ${ }_{i} c_{t}$ and ${ }_{j} e_{t}$ can be equal to zero or in (i. e. $p\left({ }_{i} c_{t},{ }_{j} e_{t}\right)=0$ ). From this relationship, the product of the eigenvalues ${ }_{i} \mathrm{C}_{t}$ and $\mathrm{j}_{\mathrm{j}}$ can be derived as

$$
{ }_{i} c_{t} \times{ }_{j} e_{t} \equiv \frac{\sigma\left({ }_{i} c_{t},{ }_{j} e_{t}\right)}{\left(p\left({ }_{i} c_{t},{ }_{j} e_{t}\right)-\left(p\left({ }_{i} c_{t}\right) \times p\left({ }_{j} e_{t}\right)\right)\right)}
$$

It is easy to extend these definitions to $n$-dimensional cases.

\section{Definition 6. The causal relationship $k\left({ }_{i} c_{t}, j e_{t}\right)$}

The deterministic relationship between cause and effect (even at quantum level) at every single Bernoulli trial $t$ is determined by the mathematical formula of the causal relationship $k\left(i_{i} c_{t} j e_{t}\right)$ as

$$
\begin{gathered}
k\left({ }_{i} c_{t},{ }_{j} e_{t}\right) \equiv \frac{\left(p\left({ }_{i} c_{t},{ }_{j} e_{t}\right)-\left(p\left({ }_{i} c_{t}\right) \times p\left({ }_{j} e_{t}\right)\right)\right)}{\sqrt{2}} \\
k\left({ }_{i} c_{t},{ }_{j} e_{t}\right) \equiv \frac{\sigma\left({ }_{i} c_{t},{ }_{i} e_{t}\right)}{\sigma\left({ }_{i} c_{t}\right) \times \sigma\left(1-p\left({ }_{i} c_{t} e_{t}\right)\right)}
\end{gathered}
$$

\section{Definition 7. The wave function in general}

Let $f\left(o C_{t}\right)$ denote any kind of a (complex, composite et cetera) mathematical function of preliminary unknown properties. In this context, the element ${ }_{o} C_{t}$ is called the argument of the (mathematical) function $f$. For each argument $o C_{t}$, a corresponding function value $y$ in given and abbreviated such that

$$
y \equiv f\left({ }_{o} C_{t}\right)
$$


In this context, $o C_{t}$ can denote (the expectation value of) a random variable, a (quantum mechanical) observable, a quantum mechanical operator, a tensor (of general relativity) or any other mathematical object. Let $\Psi\left({ }_{o} C_{t}\right)$ denote the wave function of ${ }_{o} C_{t}$. In our understanding, the wave function $\Psi\left({ }_{o} C_{t}\right)$ of ${ }_{o} C_{t}$ and the expectation value $E\left({ }_{o} C_{t}\right)$ of $o C_{t}$ are identical or $\Psi\left({ }_{o} C_{t}\right)=E\left({ }_{o} C_{t}\right)$. Thus far we define in general

$$
\begin{gathered}
\Psi\left({ }_{o} C_{t}\right) \equiv E\left({ }_{o} C_{t}\right) \\
\Psi\left({ }_{o} C_{t}\right) \equiv E\left({ }_{o} C_{t}\right) \times 1 \\
\Psi\left({ }_{o} C_{t}\right) \equiv E\left({ }_{o} C_{t}\right) \times \frac{f\left({ }_{o} C_{t}\right)}{f\left({ }_{o} C_{t}\right)} \\
\Psi\left({ }_{o} C_{t}\right) \equiv \frac{E\left({ }_{o} C_{t}\right)}{f\left({ }_{o} C_{t}\right)} \times f\left({ }_{o} C_{t}\right) \\
\Psi\left({ }_{o} C_{t}\right) \equiv A\left({ }_{o} C_{t}\right) \times f\left({ }_{o} C_{t}\right)
\end{gathered}
$$

where $A\left({ }_{o} C_{t}\right)$ denotes the (probability) amplitude of the wave function $\Psi\left({ }_{o} C_{t}\right)$. In terms of eigenfunctions we obtain the following picture.

$$
\begin{gathered}
\mathrm{E}\left({ }_{i} c_{t}\right) \equiv \mathrm{E}\left({ }_{i} c_{t}\right) \\
\mathrm{E}\left({ }_{i} c_{t}\right) \equiv \mathrm{E}\left({ }_{i} c_{t}\right) \times 1 \\
\mathrm{E}\left({ }_{i} c_{t}\right) \equiv \mathrm{E}\left({ }_{i} c_{t}\right) \times \frac{\psi\left({ }_{i} c_{t}\right)}{\psi\left({ }_{i} c_{t}\right)} \\
\mathrm{E}\left({ }_{i} c_{t}\right) \equiv \frac{\mathrm{E}\left({ }_{i} c_{t}\right)}{\psi\left({ }_{i} c_{t}\right)} \times \psi\left({ }_{i} c_{t}\right) \\
\mathrm{E}\left({ }_{i} c_{t}\right) \equiv c\left({ }_{i} c_{t}\right) \times \psi\left({ }_{i} c_{t}\right) \\
\mathrm{E}\left({ }_{i} c_{t}\right) \equiv c\left({ }_{i} c_{t}\right) \times f\left({ }_{i} c_{t}\right)
\end{gathered}
$$

where $c\left({ }_{i} c_{t}\right)$ denotes the complex coefficient as associated with the eigenvalue ${ }_{i} c_{t}$ (while satisfying some normalization condition) and $\psi\left({ }_{i} c_{t}\right)$ is the associated eigenfunction while it is equally valid that $f\left({ }_{i} c_{t}\right)=\psi\left({ }_{i} c_{t}\right)$.

Scholium.

This definition of the wave function in general is a theoretical attempt to provide a general foundation of the use of the wave function outside of quantum mechanics and without any restriction. Whether such a definition of the wave function makes any sense or not is a question of experiments and of further research. The solution of the problem of cause and effect as presented in this publication is independent of the previous definition of the wave function. In fact, the above definition of the wave function is following the simple chain rule in Leibniz (1646-1716) notation knowing to be defined something like

$$
d z \equiv \frac{d z}{d y} d y
$$

Especially, this concept of the wave function can be used even under conditions of Einstein's general theory 
of relativity too. To demonstrate the consequences of the definition of the wave function above especially under conditions of general theory of relativity let us define a co-variant second rank tensor ${ }_{o} C_{\mu v}$, such that

$$
E\left({ }_{o} C_{\mu \nu}\right) \equiv{ }_{o} C_{\mu \nu} \equiv\left[\begin{array}{llll}
c_{00} & c_{01} & c_{02} & c_{03} \\
c_{10} & c_{11} & c_{12} & c_{13} \\
c_{20} & c_{21} & c_{22} & c_{23} \\
c_{30} & c_{31} & c_{32} & c_{33}
\end{array}\right]
$$

where the individual component $c_{i k}$ of the tensor ${ }_{o} C_{\mu v}$ are treated as single expectation values. The tensor becomes in more detail as

$$
E\left({ }_{o} C_{\mu \nu}\right) \equiv{ }_{o} C_{\mu \nu} \equiv\left[\begin{array}{llll}
E\left(c_{00}\right) & E\left(c_{01}\right) & E\left(c_{02}\right) & E\left(c_{03}\right) \\
E\left(c_{10}\right) & E\left(c_{11}\right) & E\left(c_{12}\right) & E\left(c_{13}\right) \\
E\left(c_{20}\right) & E\left(c_{21}\right) & E\left(c_{22}\right) & E\left(c_{23}\right) \\
E\left(c_{30}\right) & E\left(c_{31}\right) & E\left(c_{32}\right) & E\left(c_{33}\right)
\end{array}\right]
$$

In the next context, it [9] is $\psi / \psi=1$. To each component of the tensor (i. e. an expectation value of an eigenvalue) is associated an own eigenfunction such that

$$
E\left({ }_{o} C_{\mu \nu}\right) \equiv{ }_{o} C_{\mu \nu} \equiv\left[\begin{array}{llll}
E\left(c_{00}\right) \times \frac{\psi\left(c_{00}\right)}{\psi\left(c_{00}\right)} & E\left(c_{01}\right) \times \frac{\psi\left(c_{01}\right)}{\psi\left(c_{01}\right)} & E\left(c_{02}\right) \times \frac{\psi\left(c_{02}\right)}{\psi\left(c_{02}\right)} & E\left(c_{03}\right) \times \frac{\psi\left(c_{03}\right)}{\psi\left(c_{03}\right)} \\
E\left(c_{10}\right) \times \frac{\psi\left(c_{10}\right)}{\psi\left(c_{10}\right)} & E\left(c_{11}\right) \times \frac{\psi\left(c_{11}\right)}{\psi\left(c_{11}\right)} & E\left(c_{12}\right) \times \frac{\psi\left(c_{12}\right)}{\psi\left(c_{12}\right)} & E\left(c_{13}\right) \times \frac{\psi\left(c_{13}\right)}{\psi\left(c_{13}\right)} \\
E\left(c_{20}\right) \times \frac{\psi\left(c_{20}\right)}{\psi\left(c_{20}\right)} & E\left(c_{21}\right) \times \frac{\psi\left(c_{21}\right)}{\psi\left(c_{21}\right)} & E\left(c_{22}\right) \times \frac{\psi\left(c_{22}\right)}{\psi\left(c_{22}\right)} & E\left(c_{23}\right) \times \frac{\psi\left(c_{23}\right)}{\psi\left(c_{23}\right)} \\
E\left(c_{30}\right) \times \frac{\psi\left(c_{30}\right)}{\psi\left(c_{30}\right)} & E\left(c_{31}\right) \times \frac{\psi\left(c_{31}\right)}{\psi\left(c_{31}\right)} & E\left(c_{32}\right) \times \frac{\psi\left(c_{32}\right)}{\psi\left(c_{32}\right)} & E\left(c_{33}\right) \times \frac{\psi\left(c_{33}\right)}{\psi\left(c_{33}\right)}
\end{array}\right]
$$

which can be simplified as

$$
E\left({ }_{o} C_{\mu v}\right) \equiv{ }_{o} C_{\mu \nu} \equiv\left[\begin{array}{llll}
\frac{E\left(c_{00}\right)}{\psi\left(c_{00}\right)} \times \psi\left(c_{00}\right) & \frac{E\left(c_{01}\right)}{\psi\left(c_{01}\right)} \times \psi\left(c_{01}\right) & \frac{E\left(c_{02}\right)}{\psi\left(c_{02}\right)} \times \psi\left(c_{02}\right) & \frac{E\left(c_{03}\right)}{\psi\left(c_{03}\right)} \times \psi\left(c_{03}\right) \\
\frac{E\left(c_{10}\right)}{\psi\left(c_{10}\right)} \times \psi\left(c_{10}\right) & \frac{E\left(c_{11}\right)}{\psi\left(c_{11}\right)} \times \psi\left(c_{11}\right) & \frac{E\left(c_{12}\right)}{\psi\left(c_{12}\right)} \times \psi\left(c_{12}\right) & \frac{E\left(c_{13}\right)}{\psi\left(c_{13}\right)} \times \psi\left(c_{13}\right) \\
\frac{E\left(c_{20}\right)}{\psi\left(c_{20}\right)} \times \psi\left(c_{20}\right) & \frac{E\left(c_{21}\right)}{\psi\left(c_{21}\right)} \times \psi\left(c_{21}\right) & \frac{E\left(c_{22}\right)}{\psi\left(c_{22}\right)} \times \psi\left(c_{22}\right) & \frac{E\left(c_{23}\right)}{\psi\left(c_{23}\right)} \times \psi\left(c_{23}\right) \\
\frac{E\left(c_{30}\right)}{\psi\left(c_{30}\right)} \times \psi\left(c_{30}\right) & \frac{E\left(c_{31}\right)}{\psi\left(c_{31}\right)} \times \psi\left(c_{31}\right) & \frac{E\left(c_{32}\right)}{\psi\left(c_{32}\right)} \times \psi\left(c_{32}\right) & \frac{E\left(c_{33}\right)}{\psi\left(c_{33}\right)} \times \psi\left(c_{33}\right)
\end{array}\right]
$$

Due to our known definition of i.e. $c\left(c_{00}\right)$ as $c\left(c_{00}\right)=E\left(c_{00}\right) / \psi\left(c_{00}\right)$ the tensor before simplifies as 


$$
\Psi\left({ }_{o} C_{\mu v}\right) \equiv E\left({ }_{o} C_{\mu \nu}\right) \equiv{ }_{o} C_{\mu \nu} \equiv\left[\begin{array}{llll}
c\left(c_{00}\right) \times \psi\left(c_{00}\right) & c\left(c_{01}\right) \times \psi\left(c_{01}\right) & c\left(c_{02}\right) \times \psi\left(c_{02}\right) & c\left(c_{03}\right) \times \psi\left(c_{03}\right) \\
c\left(c_{10}\right) \times \psi\left(c_{10}\right) & c\left(c_{11}\right) \times \psi\left(c_{11}\right) & c\left(c_{12}\right) \times \psi\left(c_{12}\right) & c\left(c_{13}\right) \times \psi\left(c_{13}\right) \\
c\left(c_{20}\right) \times \psi\left(c_{20}\right) & c\left(c_{21}\right) \times \psi\left(c_{21}\right) & c\left(c_{22}\right) \times \psi\left(c_{22}\right) & c\left(c_{23}\right) \times \psi\left(c_{23}\right) \\
c\left(c_{30}\right) \times \psi\left(c_{30}\right) & c\left(c_{31}\right) \times \psi\left(c_{31}\right) & c\left(c_{32}\right) \times \psi\left(c_{32}\right) & c\left(c_{33}\right) \times \psi\left(c_{33}\right)
\end{array}\right]
$$

where $\Psi\left({ }_{0} C_{\mu v}\right)$ denotes the wave function of the tensor ${ }_{o} C_{\mu v}$. In general, any tensor (of general relativity theory) can be expended in terms of its own eigenfunctions. Under these conditions, Einstein's field equations in terms of wave functions changes to

$$
\Psi\left(R_{\mu \nu}-\frac{R}{2} \times g_{\mu \nu}\right)+\Psi\left(\Lambda \times g_{\mu \nu}\right) \equiv \Psi\left(\frac{4 \times 2 \times \gamma \times \pi}{c \times c \times c \times c} \times T_{\mu \nu}\right)
$$

\section{Definition 8. The mathematical product in general}

Let $x$ denote any kind of a (complex, composite et cetera) mathematical object, function or number et cetera of preliminary unknown properties. Let $N$ denote another kind of a (complex, composite et cetera) mathematical object, function or number et cetera of preliminary unknown properties (i.e. the number of times by which $x$ is added to itself). In general, we define $N_{-} x$ as

$$
N_{-} x \equiv(x+x+x+\cdots) \equiv(1+1+1+\cdots) \times x \equiv(N) \times x \equiv N \times x
$$

\subsection{Axioms}

\section{Axiom I (Lex identitatis).}

$$
+1=+1
$$

\section{Results}

\subsection{Theorem: The Determination of the Complex Coefficient $c(1 c t)$}

\section{Claim.}

In general, the complex coefficient $c\left({ }_{1} c_{t}\right)$ as associated with the eigenvalue ${ }_{1} c_{t}$ can be calculated as

$$
c\left({ }_{1} c_{t}\right)=\frac{\psi^{*}\left({ }_{1} c_{t}\right)}{c^{*}\left({ }_{1} c_{t}\right)} \times \psi\left({ }_{1} c_{t}\right)
$$

\section{Direct proof.}

The starting point (der Ansatz) of this theorem is axiom I. According to axiom I it is

$$
+1=+1
$$

After multiplication by the complex coefficient $c\left({ }_{1} c_{t}\right)$, we obtain

$$
+1 \times c\left({ }_{1} c_{t}\right)=+1 \times c\left({ }_{1} c_{t}\right)
$$

or 


$$
c\left({ }_{1} c_{t}\right)=c\left({ }_{1} c_{t}\right)
$$

Multiplying by the $c^{*}\left({ }_{1} c_{t}\right)$, the complex conjugate of the complex coefficient $c\left({ }_{1} c_{t}\right)$ as associated with the eigenvalue ${ }_{1} c_{t}$ it is

$$
c\left({ }_{1} c_{t}\right) \times c^{*}\left({ }_{1} c_{t}\right)=c\left({ }_{1} c_{t}\right) \times c^{*}\left({ }_{1} c_{t}\right)
$$

According to Born's rule [10] this relationship is equivalent with

$$
c\left({ }_{1} c_{t}\right) \times c^{*}\left({ }_{1} c_{t}\right)=\psi\left({ }_{1} c_{t}\right) \times \varphi^{*}\left({ }_{1} c_{t}\right)
$$

and the complex coefficient $c\left({ }_{1} c_{t}\right)$ follows as

$$
c\left({ }_{1} c_{t}\right)=\frac{\varphi^{*}\left({ }_{1} c_{t}\right)}{c^{*}\left({ }_{1} c_{t}\right)} \times \psi\left({ }_{1} c_{t}\right)
$$

\section{Quod erat demonstrandum.}

\subsection{Theorem: The determination of an eigenvalue ${ }_{1} c_{t}$}

\section{Claim.}

In general, the eigenvalue ${ }_{1} C_{t}$ is determined by the equation

$$
{ }_{1} c_{t}=\frac{c\left({ }_{1} c_{t}\right)}{\varphi^{*}\left({ }_{1} c_{t}\right)}
$$

\section{Direct proof.}

The starting point (der Ansatz) of this theorem is again axiom I. According to axiom I it is

$$
+1=+1
$$

After multiplication by the complex coefficient $c\left(1 c_{t}\right)$, we obtain

$$
+1 \times c\left({ }_{1} c_{t}\right)=+1 \times c\left({ }_{1} c_{t}\right)
$$

or

$$
c\left({ }_{1} c_{t}\right)=c\left({ }_{1} c_{t}\right)
$$

According to our definition it is $E\left({ }_{1} c_{t}\right)=\psi\left({ }_{1} c_{t}\right) \times{ }_{1} c_{t} \times \psi^{*}\left({ }_{1} c_{t}\right)=c\left({ }_{1} c_{t}\right) \times \psi\left({ }_{1} c_{t}\right)$ with the consequence that $c\left({ }_{1} c_{t}\right)=E\left({ }_{1} c_{t}\right) / \psi\left({ }_{1} c_{t}\right)$. Thus far, the equation before is equivalent with

$$
c\left({ }_{1} c_{t}\right) \equiv \frac{E\left({ }_{1} c_{t}\right)}{\varphi\left({ }_{1} c_{t}\right)} \equiv \frac{\psi\left({ }_{1} c_{t}\right) \times{ }_{1} c_{t} \times \varphi^{*}\left({ }_{1} c_{t}\right)}{\varphi\left({ }_{1} c_{t}\right)}
$$

Simplifying this equation, we obtain

$$
c\left({ }_{1} c_{t}\right) \equiv{ }_{1} c_{t} \times \varphi^{*}\left({ }_{1} c_{t}\right)
$$


Thus far, if our definition $E\left({ }_{1} c_{t}\right)=c\left({ }_{1} c_{t}\right) \times \psi\left({ }_{1} c_{t}\right)$ is generally valid then we must accept too that $c\left({ }_{1} c_{t}\right)=E\left({ }_{1} c_{t}\right) / \psi\left({ }_{1} c_{t}\right)$ with the consequence that

$$
{ }_{1} c_{t}=\frac{c\left({ }_{1} c_{t}\right)}{\varphi^{*}\left({ }_{1} c_{t}\right)}
$$

\section{Quod erat demonstrandum.}

\subsection{Theorem: The Determination of an Eigenvalue ${ }_{1} c_{t}$}

\section{Claim.}

In general, the eigenvalue ${ }_{1} C_{t}$ is determined by the equation

$$
{ }_{1} c_{t}=\frac{\varphi\left({ }_{1} c_{t}\right)}{c^{*}\left({ }_{1} c_{t}\right)}
$$

\section{Direct proof.}

The starting point (der Ansatz) of this theorem is again axiom I. According to axiom I it is

$$
+1=+1
$$

After multiplication by the complex coefficient $c\left({ }_{1} c_{t}\right)$, we obtain

$$
+1 \times c\left({ }_{1} c_{t}\right)=+1 \times c\left({ }_{1} c_{t}\right)
$$

or

$$
c\left({ }_{1} c_{t}\right)=c\left({ }_{1} c_{t}\right)
$$

According to the theorems before this equation can be rearranged as

$$
c\left({ }_{1} c_{t}\right) \equiv{ }_{1} c_{t} \times \varphi^{*}\left({ }_{1} c_{t}\right)
$$

Due to another theorem before, the complex coefficient $c\left({ }_{1} c_{t}\right)$ can be substituted and the equation changes to

$$
\frac{\varphi^{*}\left({ }_{1} c_{t}\right)}{c^{*}\left({ }_{1} c_{t}\right)} \times \psi\left({ }_{1} c_{t}\right) \equiv{ }_{1} c_{t} \times \varphi^{*}\left({ }_{1} c_{t}\right)
$$

Simplifying this equation, we obtain the desired relationship as

$$
{ }_{1} c_{t} \equiv \frac{\varphi\left({ }_{1} c_{t}\right)}{c^{*}\left({ }_{1} c_{t}\right)}
$$

Quod erat demonstrandum.

\subsection{Theorem: The Definition $E\left({ }_{1} c_{t}\right)=c\left({ }_{1} c_{t}\right) \times \psi\left({ }_{1} c_{t}\right)$ Is Generally Valid} Claim. 
The definition

$$
E\left({ }_{1} c_{t}\right) \equiv \mathrm{c}\left({ }_{1} c_{\mathrm{t}}\right) \times \varphi\left({ }_{1} c_{t}\right)
$$

is generally valid.

\section{Direct proof.}

The starting point (der Ansatz) of this theorem is again axiom I. According to axiom I it is

$$
+1=+1
$$

After multiplication by the complex coefficient $c\left(1 c_{t}\right)$, we obtain

$$
+1 \times c\left({ }_{1} c_{t}\right)=+1 \times c\left({ }_{1} c_{t}\right)
$$

or

$$
c\left({ }_{1} c_{t}\right)=c\left({ }_{1} c_{t}\right)
$$

Multiplying by the $c^{*}\left({ }_{1} c_{t}\right)$, the complex conjugate of the complex coefficient $c\left({ }_{1} c_{t}\right)$ as associated with the eigenvalue ${ }_{1} c_{t}$ it is

$$
c\left({ }_{1} c_{t}\right) \times c^{*}\left({ }_{1} c_{t}\right)=c\left({ }_{1} c_{t}\right) \times c^{*}\left({ }_{1} c_{t}\right)
$$

According to Born's rule [10], this relationship is equivalent with

$$
c\left({ }_{1} c_{t}\right) \times c^{*}\left({ }_{1} c_{t}\right)=\psi\left({ }_{1} c_{t}\right) \times \psi^{*}\left({ }_{1} c_{t}\right)
$$

Rearranging equation, it is

$$
\frac{c\left({ }_{1} c_{t}\right)}{\psi^{*}\left({ }_{1} c_{t}\right)}=\frac{\psi\left({ }_{1} c_{t}\right)}{c^{*}\left({ }_{1} c_{t}\right)}
$$

Due to our theorems before (which are based on the relationship $E\left({ }_{1} c_{t}\right)=c\left({ }_{1} c_{t}\right) \times \psi\left({ }_{1} c_{t}\right)$ too), the equation is equivalent with

$$
{ }_{1} c_{t} \equiv \frac{c\left({ }_{1} c_{t}\right)}{\psi^{*}\left({ }_{1} c_{t}\right)}=\frac{\psi\left({ }_{1} c_{t}\right)}{c^{*}\left({ }_{1} c_{t}\right)} \equiv{ }_{1} c_{t}
$$

and simplifies as

Subtracting ${ }_{1} C_{t}$, it is

$$
{ }_{1} c_{t} \equiv{ }_{1} c_{t}
$$

$$
{ }_{1} c_{t}-{ }_{1} c_{t}=0=1-1
$$

or at the end

$$
+1=+1
$$

Quod erat demonstrandum. 


\section{Scholium.}

This theorem has proofed the definition $E\left({ }_{1} c_{t}\right)=c\left({ }_{1} c_{t}\right) \times \psi\left(1 c_{t}\right)$ as generally valid. Based on the definition $E\left({ }_{1} c_{t}\right)=c\left({ }_{1} c_{t}\right) \times \psi\left({ }_{1} c_{t}\right)$ we derived the theorem that

$$
{ }_{1} c_{t} \equiv \frac{c\left({ }_{1} c_{t}\right)}{\psi^{*}\left({ }_{1} c_{t}\right)}
$$

Substituting this result and the result of other theorems into Born's rule [10] we obtain $+1=+1$ which is correct and which itself proofs the definition $E\left({ }_{1} c_{t}\right)=c\left({ }_{1} c_{t}\right) \times \psi\left({ }_{1} c_{t}\right)$ as correct.

\subsection{Theorem: The Equivalence of a Wave Function $\left.\Psi_{R} E_{t}\right)$ and the Expectation Value of $E\left({ }_{R} E_{t}\right)$}

\section{Claim.}

In general, the generic state $\Psi\left({ }_{R} E_{t}\right)$ can be expressed as a superposition of eigenstates $\psi\left({ }^{2} e_{t}\right)$. In other words, every wave function $\Psi\left({ }_{R} E_{t}\right)$ can be expanded as a series involving all of the eigenfunctions $\psi\left(j e_{t}\right)$ of an operator ${ }_{R} E_{t}$ (due to the expansion postulate). Under these conditions, the wave function of a (quantum mechanical) observable and the expectation value of a random variable are identical, we obtain

$$
E\left({ }_{R} E_{t}\right)=\Psi\left({ }_{R} E_{t}\right)
$$

\section{Direct proof.}

The starting point (der Ansatz) of this theorem is again axiom I. According to axiom I it is

$$
+1=+1
$$

After multiplication by the expectation value $E\left({ }_{R} E_{t}\right)$, we obtain

$$
1 \times E\left({ }_{R} E_{t}\right)=1 \times \mathrm{E}\left({ }_{R} E_{t}\right)
$$

or

$$
E\left({ }_{R} E_{t}\right)=\mathrm{E}\left({ }_{R} E_{t}\right)
$$

According to mathematical statistics and probability theory, this equation is equivalent with

$$
E\left({ }_{R} E_{t}\right)=\mathrm{E}\left({ }_{1} e_{t}\right)+\mathrm{E}\left({ }_{2} e_{t}\right)+\mathrm{E}\left({ }_{3} e_{t}\right)+\cdots
$$

Multiplying every expectation value $E\left({ }_{j} e_{t}\right)$ of a particular eigenvalue ${ }_{j} e_{t}$ within the equation before by an associated eigenfunction term $\left(\psi\left(j e_{t}\right) / \psi\left(j e_{t}\right)\right)=1$ it follows that

$$
E\left({ }_{R} E_{t}\right)=\left(\mathrm{E}\left({ }_{1} e_{t}\right) \times \frac{\psi\left({ }_{1} e_{t}\right)}{\psi\left({ }_{1} e_{t}\right)}\right)+\left(\mathrm{E}\left({ }_{2} e_{t}\right) \times \frac{\psi\left({ }_{2} e_{t}\right)}{\psi\left({ }_{2} e_{t}\right)}\right)+\left(\mathrm{E}\left({ }_{3} e_{t}\right) \times \frac{\psi\left({ }_{3} e_{t}\right)}{\psi\left({ }_{3} e_{t}\right)}\right)+\cdots
$$

or that

$$
E\left({ }_{R} E_{t}\right)=\left(\frac{\mathrm{E}\left({ }_{1} e_{t}\right)}{\psi\left({ }_{1} e_{t}\right)} \times \psi\left({ }_{1} e_{t}\right)\right)+\left(\frac{\mathrm{E}\left({ }_{2} e_{t}\right)}{\psi\left({ }_{2} e_{t}\right)} \times \psi\left({ }_{2} e_{t}\right)\right)+\left(\frac{\mathrm{E}\left({ }_{3} e_{t}\right)}{\psi\left({ }_{3} e_{t}\right)} \times \psi\left({ }_{3} e_{t}\right)\right)+\cdots
$$


According to our general definition of $c\left(j e_{t}\right)=E\left(j e_{t}\right) / \psi\left({ }_{j} e_{t}\right)$, the equation before changes to

$$
E\left({ }_{R} E_{t}\right)=\left(\mathrm{c}\left({ }_{1} e_{t}\right) \times \psi\left({ }_{1} e_{t}\right)\right)+\left(\mathrm{c}\left({ }_{2} e_{t}\right) \times \psi\left({ }_{2} e_{t}\right)\right)+\left(\mathrm{c}\left({ }_{3} e_{t}\right) \times \psi\left({ }_{3} e_{t}\right)\right)+\cdots
$$

In general, this relationship can be rewritten as

$$
E\left({ }_{R} E_{t}\right)=\sum_{i=+1}^{i=+N}\left(\left(\mathrm{c}\left({ }_{i} e_{t}\right) \times \psi\left({ }_{i} e_{t}\right)\right)\right)
$$

According to the expansion postulate, the right term of the equation before is identical with the wave function $\Psi\left({ }_{R} E_{t}\right)$. In other words we obtain

$$
E\left({ }_{R} E_{t}\right)=\sum_{i=+1}^{i=+N}\left(\left(\mathrm{c}\left({ }_{i} e_{t}\right) \times \psi\left({ }_{i} e_{t}\right)\right)\right) \equiv \Psi\left({ }_{R} E_{t}\right)
$$

or in general

$$
E\left({ }_{R} E_{t}\right)=\Psi\left({ }_{R} E_{t}\right)
$$

\section{Quod erat demonstrandum.}

\section{Scholium.}

Still, it is important to note that this proof is based on the equation $c\left(j e_{t}\right)=E\left(j e_{t}\right) / \psi\left({ }_{j} e_{t}\right)$ or finally on the definition $E\left(j e_{t}\right)=c\left(j e_{t}\right) \times \psi\left(j e_{t}\right)$, which has been proofed as generally valid by the theorems before. Yet, the question is whether the predictions of the outcome of various experiments may provide another evidence and a highly confirmation of the definition $E\left({ }_{1} c_{t}\right)=c\left({ }_{1} c_{t}\right) \times \psi\left({ }_{1} c_{t}\right)$ and the theorems above.

Another consequence of this proof is that the wave function of a random variable and the expectation value of the same random variable are identical as proofed before. Furthermore, the expectation value of time is equivalent with the wave function ${ }_{R} \Psi(t)$ as already proofed by another publication [11].

\subsection{Theorem: The Collapse of the Wave Function}

The reduction of the state vector (i.e. collapse of the wave function) is still another crucial aspect of quantum mechanics and addresses several important, far reaching and distinct issues of the foundations of today's physics and science as such. The concept of wave function collapse was introduced for the first time by Werner Heisenberg in his 1927 paper "Über den anschaulichen Inhalt der quantentheoretischen Kinematic und Mechanik". Later, in the year 1932, the concept of wave function collapse was incorporated into the mathematical formalism of quantum mechanics by John von Neumann in his publication "Mathematische Grundlagen der Quantenmechanik". Originally, Heisenberg was writing: "durch die experimentelle Feststellung: 'Zustand $m$ ' wählen wir aus der Fülle der verschiedenen Möglichkeiten ( $\mathrm{c}_{\mathrm{nm}}$ ) eine bestimmte: $m$ aus, zerstören aber gleichzeitig, wie nachher erläutert wird, alles, was an Phasenbeziehungen noch in den Größen $\mathrm{c}_{\mathrm{nm}}$ enthalten war." [12]

In other words, a (relativistic) system evolves in time by the continuous evolution via the Schrödinger equation or some other relativistic equivalent. Under appropriate circumstances, the wave function, initially in a superposition of several eigenstates, collapses or reduces to a single eigenstate (i. e. that what is measured by a co-moving observer $O$ ). However, after the collapse of the wave function, a physical system is again determined or described by a wave function. 


\section{Claim.}

In general, the collapse of the wave function is determined by the equation

$$
\left(\mathrm{c}\left({ }_{1} c_{t}\right) \times \psi\left({ }_{1} c_{t}\right)\right)=\Psi\left({ }_{o} C_{t}\right) \times\left(1-\frac{\left(\mathrm{c}\left({ }_{1} \underline{c}_{t}\right) \times \psi\left({ }_{1} \underline{c}_{t}\right)\right)}{\Psi\left({ }_{o} C_{t}\right)}\right)
$$

\section{Direct proof.}

The starting point (der Ansatz) of this theorem is again axiom I. According to axiom I it is

$$
+1=+1
$$

After multiplication by the wave function, we obtain

$$
1 \times \Psi\left({ }_{o} C_{t}\right)=1 \times \Psi\left({ }_{o} C_{t}\right)
$$

or

$$
\Psi\left({ }_{o} C_{t}\right)=\Psi\left({ }_{o} C_{t}\right)
$$

According to the so-called expansion postulate, a fundamental postulate of quantum mechanics, the equation before changes to

$$
\Psi\left({ }_{o} C_{t}\right)=\left(\mathrm{c}\left({ }_{1} c_{t}\right) \times \psi\left({ }_{1} c_{t}\right)\right)+\left(\mathrm{c}\left({ }_{2} c_{t}\right) \times \psi\left({ }_{2} c_{t}\right)\right)+\left(\mathrm{c}\left({ }_{3} c_{t}\right) \times \psi\left({ }_{3} c_{t}\right)\right)+\cdots
$$

which can be simplified as

$$
\begin{aligned}
& \Psi\left({ }_{o} C_{t}\right)=\left(\mathrm{c}\left({ }_{1} c_{t}\right) \times \psi\left({ }_{1} c_{t}\right)\right)+\left(\mathrm{c}\left({ }_{2} c_{t}\right) \times \psi\left({ }_{2} c_{t}\right)\right)+\left(\mathrm{c}\left({ }_{3} c_{t}\right) \times \psi\left({ }_{3} c_{t}\right)\right)+\cdots \\
& \Psi\left({ }_{o} C_{t}\right)=\left({ }_{c}\left({ }_{1} c_{t}\right) \times \psi\left({ }_{1} c_{t}\right)\right)+\underbrace{\left.\left(\mathrm{c}\left({ }_{2} c_{t}\right) \times \psi\left({ }_{1} c_{t}\right)\right) \times \psi\left({ }_{1} c_{t}\right)\right)}_{\left({ }_{1}\right)} \\
& \Psi\left({ }_{o} C_{t}\right)=\left(\mathrm{c}\left({ }_{3} c_{t}\right) \times \psi\left({ }_{3} c_{t}\right)\right)+\cdots
\end{aligned}
$$

where $\mathrm{c}\left({ }_{1} \underline{\underline{c}}\right)$ denotes the complex coefficient of anti ${ }_{1} \mathrm{c}_{\mathrm{t}}$ and $\psi\left({ }_{1} \underline{\mathrm{C}}_{\mathrm{t}}\right)$ denotes the anti-eigenfunction. Rearranging equation before yields

$$
\frac{\Psi\left({ }_{o} C_{t}\right)}{\Psi\left({ }_{o} C_{t}\right)}=\frac{\left(\mathrm{c}\left({ }_{1} C_{t}\right) \times \psi\left({ }_{1} c_{t}\right)\right)}{\Psi\left({ }_{o} C_{t}\right)}+\frac{\left(\mathrm{c}\left({ }_{1} \underline{c}_{t}\right) \times \psi\left({ }_{1} \underline{c}_{t}\right)\right)}{\Psi\left({ }_{o} C_{t}\right)}
$$

In other words, it is

$$
\frac{\left(\mathrm{c}\left({ }_{1} c_{t}\right) \times \psi\left({ }_{1} c_{t}\right)\right)}{\Psi\left({ }_{o} C_{t}\right)}=1-\frac{\left(\mathrm{c}\left({ }_{1} \underline{c}_{t}\right) \times \psi\left({ }_{1} \underline{C}_{t}\right)\right)}{\Psi\left({ }_{o} C_{t}\right)}
$$

and equally 


$$
\frac{\left(\mathrm{c}\left({ }_{1} C_{t}\right) \times \psi\left({ }_{1} c_{t}\right)\right) \times \Psi\left({ }_{o} C_{t}\right)}{\Psi\left({ }_{o} C_{t}\right) \times \Psi\left({ }_{o} C_{t}\right)}=1-\frac{\left(\mathrm{c}\left({ }_{1} \underline{C}_{t}\right) \times \psi\left({ }_{1} \underline{C}_{t}\right)\right) \times \Psi\left({ }_{o} C_{t}\right)}{\Psi\left({ }_{o} C_{t}\right) \times \Psi\left({ }_{o} C_{t}\right)}
$$

or

$$
\left(\mathrm{c}\left({ }_{1} c_{t}\right) \times \psi\left({ }_{1} c_{t}\right)\right)=\Psi\left({ }_{o} C_{t}\right) \times\left(1-\frac{\left(\mathrm{c}\left({ }_{1} \underline{c}_{t}\right) \times \psi\left({ }_{1} \underline{c}_{t}\right)\right)}{\Psi\left({ }_{o} C_{t}\right)}\right)
$$

\section{Quod erat demonstrandum.}

\section{Scholium.}

Thus far, it is known that the term

$$
\mathrm{c}\left({ }_{1} c_{t}\right) \times \psi\left({ }_{1} c_{t}\right)
$$

describes the situation after the collapse of the wave function $\Psi\left(o C_{t}\right)$ into one of the eigenstates of the observable being measured while the wave function itself denotes the set of all eigenstates/eigenvalues, i. e. the situation before the collapse of itself into an eigenvalue and an eigenfunction. In this context, it appears to be that the term

$$
\left(1-\frac{\left(\mathrm{c}\left({ }_{1} \underline{c}_{t}\right) \times \psi\left({ }_{1} \underline{c}_{t}\right)\right)}{\Psi\left({ }_{o} C_{t}\right)}\right)
$$

describes something like the process of the collapse of the wave function itself. Whether the last term is related to something like the Lorenz transformation $\left(1-\left(\mathrm{v}^{2} / \mathrm{c}^{2}\right)\right)$ is a point of further research.

\subsection{Theorem: The Mathematical Formula of the Causal Relationship $k$}

Meanwhile, the mathematical formula of the causal relationship is presented to the public under several [7], [13]-[22] circumstances. The purpose of this publication is to provide a new approach strictly from the standpoint of quantum theory.

Thesis (Claim).

The deterministic relationship between cause and effect at a single Bernoulli trial $t$ is determined by the mathematical formula of the causal relationship $k\left({ }_{i} c_{t}, i e_{t}\right)$ as

$$
\begin{gathered}
k\left({ }_{i} c_{t},{ }_{j} e_{t}\right) \equiv \frac{\left(p\left({ }_{i} c_{t},{ }_{j} e_{t}\right)-\left(p\left({ }_{i} c_{t}\right) \times p\left({ }_{j} e_{t}\right)\right)\right)}{\sqrt{2}} \\
k\left({ }_{i} c_{t},{ }_{j} e_{t}\right) \equiv \frac{\sigma\left({ }_{i} c_{t} c_{t}\right) \times\left(1-p\left({ }_{i} c_{t}\right)\right)}{\sigma\left({ }_{i} c_{t}\right) \times \sigma\left({ }_{j} e_{t}\right)}
\end{gathered}
$$

\section{Proof.}

Again, our starting point (der Ansatz) is axiom I. Thus far, it is

$$
+1=+1
$$


Multiplying by the eigenvalue of the cause ${ }_{i} c_{t}$, we obtain

$$
1 \times{ }_{i} c_{t}=1 \times{ }_{i} c_{t}
$$

or

$$
{ }_{i} c_{t}={ }_{i} c_{t}
$$

Multiplying this equation by an eigenvalue of an effect $e_{t}$, it is

$$
{ }_{i} c_{t} \times{ }_{j} e_{t}={ }_{i} c_{t} \times{ }_{j} e_{t}
$$

The eigenvalue of the effect ${ }_{j} e_{t}$ is known to be defined as

$$
{ }_{j} e_{t} \equiv \frac{\sigma\left({ }_{j} e_{t}\right)}{\sqrt[2]{p\left({ }_{j} e_{t}\right) \times\left(1-p\left({ }_{j} e_{t}\right)\right)}}
$$

Substituting this relationship into the equation before, we obtain

$$
{ }_{i} c_{t} \times \frac{\sigma\left({ }_{j} e_{t}\right)}{\sqrt[2]{p\left({ }_{j} e_{t}\right) \times\left(1-p\left({ }_{j} e_{t}\right)\right)}}={ }_{i} c_{t} \times{ }_{j} e_{t}
$$

The eigenvalue of the cause ${ }_{i} c_{t}$ is known to be defined as

$$
{ }_{i} c_{t} \equiv \frac{\sigma\left({ }_{i} c_{t}\right)}{\sqrt[2]{p\left({ }_{i} c_{t}\right) \times\left(1-p\left({ }_{i} c_{t}\right)\right)}}
$$

Substituting this relationship into the equation before, it is

$$
\frac{\sigma\left({ }_{i} c_{t}\right)}{\sqrt[2]{p\left({ }_{i} c_{t}\right) \times\left(1-p\left({ }_{i} c_{t}\right)\right)}} \times \frac{\sigma\left({ }_{j} e_{t}\right)}{\sqrt[2]{p\left({ }_{j} e_{t}\right) \times\left(1-p\left({ }_{j} e_{t}\right)\right)}}={ }_{i} c_{t} \times{ }_{j} e_{t}
$$

The product of the two eigenvalues ${ }_{i} c_{t}$ and effect ${ }_{j} e_{t}$ was derived as

$$
{ }_{i} c_{t} \times{ }_{j} e_{t} \equiv \frac{\sigma\left({ }_{i} c_{t},{ }_{j} e_{t}\right)}{\left(p\left({ }_{i} c_{t},{ }_{j} e_{t}\right)-\left(p\left({ }_{i} c_{t}\right) \times p\left({ }_{j} e_{t}\right)\right)\right)}
$$

Substituting this relationship into the equation before, it follows that

$$
\frac{\sigma\left({ }_{i} c_{t}\right)}{\sqrt[2]{p\left({ }_{i} c_{t}\right) \times\left(1-p\left({ }_{i} c_{t}\right)\right)}} \times \frac{\sigma\left({ }_{j} e_{t}\right)}{\sqrt[2]{p\left({ }_{j} e_{t}\right) \times\left(1-p\left({ }_{j} e_{t}\right)\right)}}=\frac{\sigma\left({ }_{i} c_{t},{ }_{j} e_{t}\right)}{\left(p\left({ }_{i} c_{t},{ }_{j} e_{t}\right)-\left(p\left({ }_{i} c_{t}\right) \times p\left({ }_{j} e_{t}\right)\right)\right)}
$$


The equation can be simplified as

$$
\frac{\left(p\left({ }_{i} c_{t},{ }_{j} e_{t}\right)-\left(p\left({ }_{i} c_{t}\right) \times p\left({ }_{j} e_{t}\right)\right)\right)}{\sqrt[2]{p\left({ }_{i} c_{t}\right) \times\left(1-p\left({ }_{i} c_{t}\right)\right) \times p\left({ }_{j} e_{t}\right) \times\left(1-p\left({ }_{j} e_{t}\right)\right)}}=\frac{\sigma\left({ }_{i} c_{t},{ }_{j} e_{t}\right)}{\sigma\left({ }_{i} c_{t}\right) \times \sigma\left({ }_{j} e_{t}\right)}
$$

The mathematical formula of the causal relationship $k\left(i c_{t} e_{t}\right)$ follows as

$$
k\left({ }_{i} c_{t},{ }_{j} e_{t}\right) \equiv \frac{\left(p\left({ }_{i} c_{t},{ }_{j} e_{t}\right)-\left(p\left({ }_{i} c_{t}\right) \times p\left({ }_{j} e_{t}\right)\right)\right)}{\sqrt[2]{p\left({ }_{i} c_{t}\right) \times\left(1-p\left({ }_{i} c_{t}\right)\right) \times p\left({ }_{j} e_{t}\right) \times\left(1-p\left({ }_{j} e_{t}\right)\right)}}=\frac{\sigma\left({ }_{i} c_{t},{ }_{j} e_{t}\right)}{\sigma\left({ }_{i} c_{t}\right) \times \sigma\left({ }_{j} e_{t}\right)}
$$

\section{Quod erat demonstrandum.}

Remark 6. The range of the causal relationship is

$$
-1 \leq k\left({ }_{i} c_{t},{ }_{j} e_{t}\right) \leq+1
$$

\section{Discussion}

The mathematical formula of the causal relationship $\mathrm{k}$ is grounded on a primary local-realistic approach to the relationship between cause and effect and on the law of independence known as

$$
p\left({ }_{i} c_{t},{ }_{j} e_{t}\right)-\left(p\left({ }_{i} c_{t}\right) \times p\left({ }_{j} e_{t}\right)\right)
$$

with the consequence that the causal relationship $k\left(i c_{t}, j e_{t}\right)$ at quantum level follows as

$$
k\left({ }_{i} c_{t},{ }_{j} e_{t}\right) \equiv \frac{\left(p\left({ }_{i} c_{t},{ }_{j} e_{t}\right)-\left(p\left({ }_{i} c_{t}\right) \times p\left({ }_{j} e_{t}\right)\right)\right)}{\sqrt[2]{p\left({ }_{i} c_{t}\right) \times\left(1-p\left({ }_{i} c_{t}\right)\right) \times p\left({ }_{j} e_{t}\right) \times\left(1-p\left({ }_{j} e_{t}\right)\right)}}=\frac{\sigma\left({ }_{i} c_{t},{ }_{j} e_{t}\right)}{\sigma\left({ }_{i} c_{t}\right) \times \sigma\left({ }_{j} e_{t}\right)}
$$

Still, these consideration of a local-realistic and deterministic relationship between cause and effect backgrounded by probability theory neither disables nor disproof's non-locality. This should not suggest that the formula above is the only mathematical way to express the relationship between cause and effect. It is possible to formulate the mathematical formula of causal relationship k even under conditions of general theory of relativity [23] in the language of tensors.

\section{Conclusion}

The mathematical formula of the causal relationship $k\left({ }_{i} c_{t}{ }_{j} e_{t}\right)$ represents an experimentally testable, probability (quantum) theory based, deterministic, mathematical concept of the relationship between cause and effect.

\section{Acknowledgment}

I am very happy to have the opportunity to express my very deep gratitude to the Scientific Committee of the international conference "Quantum and Beyond (QB)", at the Linnaeus University in Växjö, Sweden, June 13-16, 2016, an international conference devoted to quantum theory and experiment. This paper has been accepted for presentation and was presented at the conference "Quantum and Beyond (QB)". 


\section{References}

[1] Heisenberg, W. (1927). Über den anschaulichen Inhalt der quantentheoretischen Kinematik and Mechanik. Zeitschrift für Physik, 43, 197.

[2] Bohr, N. (1950). On the notions of causality and complementarity. Science, 111, 51-54.

[3] Bohr, N. (1937). Causality and complementarity. Philosophy of Science, 4, 291.

[4] Barukčić, I. (2011). Anti Heisenberg - Refutation of Heisenberg's uncertainty relation. American Institute of Physics-Conference Proceedings, 322.

[5] Barukčić, I. (2014). Anti Heisenberg - Refutation of Heisenberg's uncertainty principle. International Journal of Applied Physics and Mathematics, 4, 244-250.

[6] Barukčić, I. (2016). Anti Heisenberg - The end of Heisenberg's uncertainty principle. Journal of Applied Mathematics and Physics, 4, 881-887.

[7] Barukčić, I. (2016). The mathematical formula of the causal relationship k. International Journal of Applied Physics and Mathematics, 6, 45-65.

[8] Aharonov, Y., Anandan, J., \& Vaidman, L. (1993). Meaning of the wave function. Physical Review A (Atomic, Molecular, and Optical Physics), 47, 4616-4626.

[9] Barukčić, I. (2016). Anti aristotle - The division of zero by zero. Journal of Applied Mathematics and Physics, 4, 749-761.

[10] Born, M. (1926). Zur Quantenmechanik der Stoßvorgänge. Zeitschrift für Physik, 37, 363-367.

[11] Barukčić, I. (2016). The physical meaning of the wave function. Journal of Applied Mathematics and Physics, 4, 988-1023.

[12] Heisenberg, W. (1927) Über den anschaulichen Inhalt der quantentheoretischen Kinematik und Mechanik. Zeitschrift für Physik, 43, 183.

[13] Barukčić, I. (1989). Die Kausalität, (First German Edition). Hamburg: Wissenschaftsverlag. 218.

[14] Barukčić, I. (1997). Die Kausalität. (Second German Edition). Wilhelmshaven: Scientia. 374.

[15] Barukčić, I. (2005). Causality. New Statistical Methods. (First English Edition). Hamburg: Books on Demand. 488.

[16] Barukčić, I. (2006). Causality. New Statistical Methods. (Second English Edition). Hamburg: Books on Demand. 488.

[17] Thompson, M. E. (2006). Reviews. Causality. New statistical methods. International Statistical Institute, 26(1), 6.

[18] Barukčić, I. (2006). New method for calculating causal relationships. Proceedings of XXIIIrd International Biometric Conference.

[19] Barukčić, I. (2006). Causation and the law of independence. Proceedings of Symposium on Causality 2006.

[20] Barukčić, I. (2011). Causality I. A Theory of Energy, Time and Space. Morrisville: Lulu. 648.

[21] Barukčić, I. (2011). Causality II. A Theory of Energy, Time and Space. Morrisville: Lulu. 376.

[22] Barukčić, I. (2012). The deterministic relationship between cause and effect. Proceedings of International Biometric Conference.

[23] Barukčić, I. (2016) Unified field theory. Journal of Applied Mathematics and Physics, 4(8), 1379-1438.

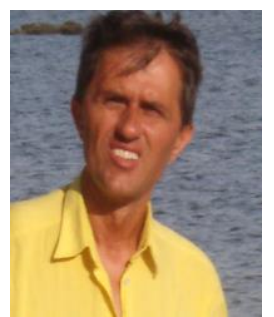

Ilija Barukčić was born on October 1'th 1961 in Novo Selo (Bosina and Hercegovina, former Yugoslavia). Barukčić studied at the University of Hamburg, Germany (1982-1989) human medicine (philosophy and physics). He graduated at the University of Hamburg, Germany with the degree: State exam. Barukčićs basic field of research is the relationship between cause and effect under conditions of quantum and relativity theory, in biomedical sciences, in philosophy et cetera. 
Thus far, among his several publications in physics are the refutation of Heisenberg's uncertainty principle (Ilija Barukčić, "Anti Heisenberg - Refutation Of Heisenberg's Uncertainty Relation," American Institute of Physics - Conference Proceedings, Volume 1327, pp. 322-325, 2011), the refutation of Bell's theorem and the CHSH inequality (Ilija Barukčić, "Anti-Bell - Refutation of Bell's theorem," American Institute of Physics - Conference Proceedings, Volume 1508, pp. 354-358, 2012). In another publication, Barukčić was able to provide the proof that time and gravitational field are equivalent (Ilija Barukčić, "The Equivalence of Time and Gravitational Field," Physics Procedia, Volume 22, pp. 56-62, 2011). Barukčić solved the long lasting problem of the particle and the wave (Ilija Barukčić, "The Relativistic Wave Equation," International Journal of Applied Physics and Mathematics vol. 3, no. 6, pp. 387-391, 2013.) and refuted Heisenberg's uncertainty once again in general (Ilija Barukčić, "Anti Heisenberg - Refutation of Heisenberg's Uncertainty Principle," International Journal of Applied Physics and Mathematics vol. 4, no. 4, pp. 244-250, 2014.). Barukčić was able to provide a mathematical proof that neither Einstein's cosmological constant $\Lambda$ (Ilija Barukčić, "Anti Einstein - Refutation of Einstein's General Theory of Relativity," International Journal of Applied Physics and Mathematics vol. 5, no. 1, pp. 18-28, 2015.) nor Newton's gravitational constant $\gamma$ (Ilija Barukčić, "Anti Newton - Refutation of the Constancy of Newton's Gravitational Constant Big G," International Journal of Applied Physics and Mathematics vol. 5, no. 2, pp. 126-136, 2015.) are constant. 